poorer the solubility of a drug the more refined must be the formulation techniques to ensure satisfactory disintegration and dissolution. In such cases non-equivalence may be assumed until evidence of bioavailability is supplied. Often the original branded preparation has been shown to have superior bioavailability, and this has led to prescribing by brand name, which is discouraged by the Department of Health on grounds of economy. To imagine that nonbranded products are invariably inferior would be false. Nevertheless when the range of bioavailability is wide, brand prescribing of a product from a reputable manufacturer has the distinct advantage of ensuring that repeat prescriptions do not subject patients to fluctuating bioavailability.

The situation with Lanoxin provides a rare exception to this general rule. In May this year an adjustment in manufacturing techniques resulted in an unsuspected and fortuitously discovered twofold increase in the bioavailability of digoxin. To change from other brands of digoxin or from "old" Lanoxin to "new" Lanoxin is effectively to double the dose, leading to the risk of digoxin toxicity. The risk is real but small, for the majority of patients are satisfactorily digitalized with steady-state plasma digoxin levels well below the toxic range. The reaction of the council of the Pharmaceutical Society after consultation with the Committee on Safety of Medicines ${ }^{7}$ has been to advise pharmacists not to dispense Lanoxin on receiving open prescriptions for digoxin. This would be a reasonable precaution if it were certain that the range of bioavailability from other brands of digoxin is less than the twofold difference between "old" and "new" Lanoxin. But this is not certain. Indeed, there is evidence to the contrary. ${ }^{8}$ That being so, it might be more prudent to advise that prescriptions for digoxin should specify manufacturer or brand, and that each patient should stick to the same source.

One thing is certain, doctors will want to be assured that the products they prescribe are reliable and they will want to know the bioavailability of different brands, though it will be difficult to provide them with that information. Measurement of bioavailability may involve pharmacodynamic studies-that is, observing response to drugs, doing plasma level estimations, and studying cumulative urinary excretion. It has been stated that "if tests in human subjects constitute the only reliable method of demonstrating therapeutic equivalence, an unacceptably large burden will be imposed on drug manufacturers." 9 Certainly in-vitro dissolution tests, though not completely predictive, do correlate fairly well with plasma levels and yield information which is probably adequate for most drugs. But if in individual cases there remains a doubt about equivalence which might significantly affect efficacy or safety then in-vivo studies will have to be performed.

It would seem reasonable to expect that eventually official tolerance limits will be set on bioavailability. Such a situation would help the prescriber but should not lure him into a false sense of security. Patients will always vary in sensitivity, and it will still be necessary to adjust the dose according to the response.

1 British Medical fournal, 1972, 3, 427.

\& British Medical Fournal, 1968, 1, 781.

British Medical fournal, 1969, 1,2.

4 Shaw, T. R. D., Howard, M. R., and Hamer, J., Lancet, 1972, 2, 303.

s Whittet, T. D., Prescribers' fournal, 1971, 11, 48.

- Tyrer, J. H., Eadie, M. J., Sutherland, J. M., and Hooper, W. D., British Medical fournal, 1970, 4, 271.

'Pharmaceutical fournal, 1972, 209, 133

8 Beckett, A. H., and Cowan, D. A., Pharmaceutical fournal, 1972, 209, 174.

- Subcommittee of the Policy Advisory Committee, Drug Efficacy Study, fournal of the American Medical Association, 1969, 208, 1171.

\section{Carcinoembryonic Antigen}

To devise tests for the detection of cancer by immunological methods has been the aim of several research teams during recent years. One of the more promising lines of investigation is to detect in the tumours of adult patients macromolecules associated with fetal tissue growth.

P. Gold and S. O. Freeman ${ }^{1}$ in 1965 first described an antigen present in extracts from adenocarcinoma of the colon and fetal colonic mucosa but absent from extracts of normal colon and the unaffected parts of cancer-bearing colon. It was initially thought to be limited to fetal gastrointestinal tract, liver, and pancreas and to cancer of the colon. Hence its name, carcinoembryonic antigen. The development of a radioimmunoassay capable of detecting nanogram $\left(10^{-9} \mathrm{~g}\right)$ quantities of the antigen in the plasma ${ }^{2}$ opened the way for measuring levels of it in patients with cancer. At first it seemed that a raised level of carcinoembryonic antigen in plasma was specific to the cancer and an indication of gastrointestinal cancer, and there was enthusiastic talk at one time of using the test for population screening.

Since then modifications of the radioimmunoassay technique have led to raised levels of the antigen being detected in patients with a variety of cancers outside the gastrointestinal tract and even with some benign diseases. ${ }^{3}$ The latest of these reports come from the Chester Beatty Research Institute and are published in the B.M.F. this week at pages 605 and 609 . They confirm that a raised plasma level of carcinoembryonic antigen lacks the specificity that was hoped for earlier. It is agreed that the antigen is a glycoprotein, and it is possible that the recent techniques for its measurement are not detecting the identical antigen that reacts with Gold's specific antisera. No doubt part of this confusion will be resolved as the immunochemists identify more precisely what the assay system is measuring.

The present position seems to be that carcinoembryonic antigen or material like it can be released from normal tissues, inflammatory and hypertrophic lesions, and tumours of various histological types. This makes any population screening impracticable, particularly if cancers in their early stages are associated with low rises in the concentration of the antigen. The quantity of carcinoembryonic antigen detected is higher in association with some tumours than with others. Likewise the frequency of positive tests is high in cases of tumours of the bowel and lung and neuroblastoma, ${ }^{3}$ while it is more sporadic with other types of cancer.

Does this mean that studies of this antigen have now become academic, or have they still something to offer the clinician? The Chester Beatty team have addressed them- $N$ selves to this question. As a raised plasma concentration of $\mathrm{\omega}$ the antigen usually falls after successful excision of the tumour, this test may prove to be valuable for monitoring patients after primary surgical operation or radiotherapy. $\stackrel{\mathcal{D}}{+}$ Only time will tell if a rising concentration of the antigen in plasma or urine in cases of bladder cancer can serve to predict a recurrence of the tumour before the standard $\stackrel{\Phi}{\stackrel{\Phi}{Q}}$ clinical methods will detect it during follow-up. In cases of $\stackrel{\mathbb{Q}}{\varrho}$ colonic or rectal cancer the amount of tumour and the levels of the antigen appear to be related, ${ }^{4}$ but this is not $\delta$ necessarily so in other forms of cancer. A relationship of this kind wil be of paramount importance when assessing 흘 the growth of tumours in which the early treatment of re- $?$ currence or secondary spread has a reasonable chance of prolonging life. 
1 Gold, P., and Freeman, S. O., fournal of Experimental Medicine, $1965,121,439$

Thomson, D. M. P., Krupey, J., Freedman, S. O., and Gold, P. Proceedings of the National Academy of Sciences, 1969, 64, 161 Reynoso, G., et al., fournal of the American Medical Association, 1972, 220, 361.

LoGerfo, P., LoGerfo, F., Herter, F., Barker, H. G., and Hansen, H. J., Amercian fournal of Surgery, 1972, 123, 127.

\section{Geriatric Plans}

Since the end of the second world war geriatric medicine in the United Kingdom has developed from a specialty practised by a few enthusiasts to a well-recognized discipline employing more than 270 consultant physicians and reaching a standard higher than anywhere else in the world. In 1967 the Royal College of Physicians acknowledged this progress by setting up a committee to consider its standing and development as a special branch of general medicine. The report of this committee has now been released.

The report is brief, covering some twelve pages, and is easily read. It starts by defining geriatric medicine and suggesting aspects of the subject which are particularly important to the elderly sick. These include the part played by disability, mental capacity, and social background in the elderly patient and the importance of accurate diagnosis in making a full assessment of the patient's state. Consequently the report considers that most geriatric inpatient beds should be in the district general hospitals, though it agrees that some patients may be admitted to wards in smaller hospitals near their homes for continuing care.

In discussing the present position the report emphasizes that many geriatric departments are short of staff and facilities. Many of the buildings which at present house elderly patients are in a poor state, but the high work load and responsibility of physicians in geriatric medicine is only inferred. Nevertheless from the continuing tone of the report it is obvious that the committee was worried by the number of unfilled consultant posts and the problems of recruiting more people to the specialty. As an alternative to the fully committed physician in geriatric medicine they have suggested that some physicians might have defined commitments in both geriatric and general medicine. This type of appointment already exists, and the need for experiments of this nature has been suggested elsewhere. ${ }^{1}$ The importance of co-operation between the physician in geriatric medicine and his colleagues is rightly stressed, for the problems of ageing involve many disciplines. The report emphasizes that the geriatrician has many parts to play and suggests that in large units individuals may elect to fill a specific role. The report has little to say about the lone consultant in a small unit, and indeed the problems of professional isolation experienced by some doctors are ignored.

In discussing future trends it is disappointing that the committee has not been more constructive, though few readers will quarrel with what it does say. It is the lack of new ideas which causes concern. There is for instance no mention of the importance of increasing turnover of beds within geriatric units. Instead it is suggested that increasing numbers of beds will be necessary during the next 30 years, yet $R$. W. Parnell 2 has suggested that if turnover is increased sufficient beds are available to cater for the expected increased number of elderly.

The report deals most adequately with the subject of further education and training posts and makes the important point that there is great satisfaction to be had in the specialty of geriatric medicine. If this can be demonstrated to undergraduate and postgraduate students, there is no doubt that the problems of recruitment into the specialty will be solved. Correctly, the report says that teaching should extend through every phase of the undergraduate curriculum, including the preclinical period.

Research is essential if the advance of geriatric medicine is to continue, and the report suggests that this be collaborative or individual. Collaborative ventures are difficult to organize, as is research on a longitudinal basis. To foster these it seems essential that an institute of gerontology and geriatrics similar to those in America and Russia is established soon. It seems a pity that the committee did not consider this possibility and pronounce upon it.

On the whole this is a fair report if at times pedestrian. There is a genuine problem of recruitment of hospital doctors to geriatric medicine. The importance of attractive buildings, efficient organization, and helpful co-operation with other specialties cannot be stressed too highly. The image of the job in question is all-important. If working conditions are bad, no amount of satisfaction in the job will compensate. Geriatric medicine has to overcome this problem. If the report's suggestions are adopted the position should improve. But immediately to replace the bad buildings and to increase the number of geriatric beds is unrealistic, since it will require too great an expenditure of capital and revenue. As the report recommends, more must be done to promote a healthy mental and physical environment for all people over 65. What should be done the report does not say: perhaps it was outside the committee's brief. Some other committee, perhaps from the B.M.A., will have to provide the answers.

1 Age and Ageing, 1972, 1, 129.

2 Parnell, R., Gerontologia clinica, 1971, 13, 136.

\section{Medicine among the Managers}

The professional life of most doctors doing clinical medicine in the N.H.S. usually touches the organization of the Service in only a limited way. The general practitioner conducts his surgery and visits his patients in a medical environment which is still largely fashioned by his own or his partners' wishes. Personal contacts with the executive council are infrequent, while the Elephant and Castle is a remote address. The consultant doing his ward round or the houseman examining a late night admission knows that his surroundings and equipment are provided by the hospital authority, but he is usually too busy to spare more than a thought-and then probably a critical one-for the complicated organization supporting the hospital service.

Thus the Green Papers, ${ }^{12}$ the consultative document, ${ }^{3}$ the subsequent discussion, and the resultant White Paper on N.H.S. reorganization, ${ }^{4}$ though not unnoticed by the average busy clinician, have probably been passed by with only a cursory glance and a thought that 1974 is a long way off. Now a Management Study Report has been published.5 It deserves closer study than it is likely to get, for though its proposals are designed to affect the working lives of doctors they are set out in a jargon that will deter any but professional readers of such documents from penetrating its secrets. 